\title{
Production of Customized Reactors by 3D Printing for Corrosive and Exothermic Reactions
}

\author{
Carlos A. Grande* and Terje Didriksen
}

Cite This: https://doi.org/10.1021/acs.iecr.1c02791

Read Online

ACCESS

Wll Metrics \& More

Article Recommendations

Supporting Information

ABSTRACT: This work presents a continuous reactor designed to be produced by $3 \mathrm{D}$ printing with the ultimate objective of performing fast, exothermic, and corrosive reactions. The dilution of sulfuric acid with water was used as a model for reactor design. A good mixing inside the reactor will promote the dilution and at the same time increase the heat transfer. Fast heat transfer is important to avoid vaporization of reactants/products and to control corrosion inside the reactor. The reactor was designed using a genetic algorithm to maximize the surface area of a prespecified reactor volume while ensuring a good mixing of the reactants. We have experimentally demonstrated that dilution of sulfuric acid can be done continuously in a HartridgeRoughton mixer with lattices for enhanced heat transfer. Selected designs with internal and external lattices for enhanced heat exchange were manufactured by $3 \mathrm{D}$ printing using the Ti64 alloy. Different printing services were used to

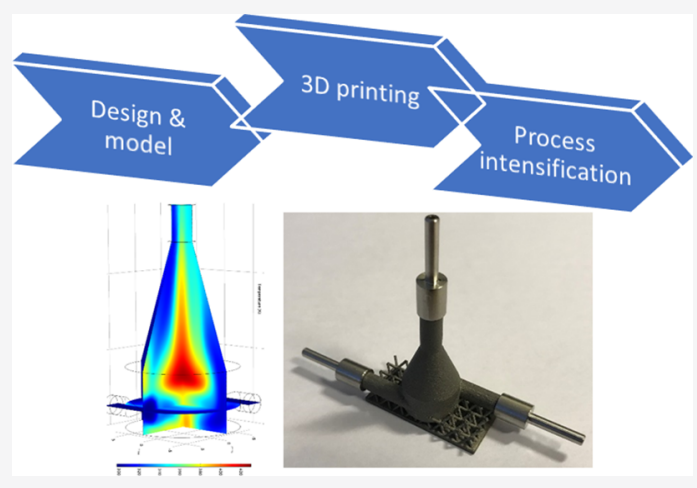
compare the quality of reactors that can be achieved by new industrial players that do not possess a $3 \mathrm{D}$ printer. One important item that should be considered when $3 \mathrm{D}$ printing is used for corrosive reactions is cross-contamination with other metals, since that can significantly affect the life and safety conditions of the reactors.

\section{INTRODUCTION}

Continuous manufacturing has been recognized recently as one of the important routes to promote process intensification of chemical and pharmaceutical reactors. ${ }^{1-10}$ While several advantages were previously attributed to continuous manufacturing, the technology had a worldwide impact in the mass production of COVID vaccines. ${ }^{11}$

In the production of fine chemicals and pharmaceutical compounds, batch reactors are dominant in the industrial landscape. The possibility of using the same batch reactor for multiple reactions, the detailed know-how of the standard operating protocols (SOPs) by the operators, and the documentation for good manufacturing practices (GMP) are strong reasons to keep on using this technology. There are several reactions that use corrosive chemicals, and/or in some cases, the heat of reaction is very large. ${ }^{12-14}$ When performing highly exothermic reactions in batch reactors, it is common to dilute the reactants to enhance the overall heat capacity within the reactor. Such dilution requires increased efforts in separation stages, consuming additional energy. Moreover, the dilution of the reactants implies that a larger reactor will be used to produce a smaller amount of product. If these products are dangerous or corrosive, more safety measures should be put in place. The large footprint, the extra cost of separation, and the safety of rather large equipment increase the overall cost of production. Recent advances in manufacturing technologies for production of reactors may change this practice toward a more economic and sustainable production.
Additive manufacturing technologies like 3D printing can have an unprecedented effect in boosting efficiency of reactors and, in general, of chemical engineering, due to the large possibilities of customization. This technology enables the construction of a reactor that is targeted to perform a given chemistry instead of tailoring the operating conditions of a standard reactor to fit the chemistry. ${ }^{15-18}$ In recent years, there have been more and more publications dealing with 3D printed reactors. ${ }^{19,20}$ While a large fraction of the publications deals with production of reactors in polymer and as labware, some recent publications are targeting reactors made in metal that improve simultaneously the reaction conversion and/or selectivity, together with heat transfer. ${ }^{21-23}$

In the production of fine chemicals and pharmaceutical components, it is common to use $50 \%$ or $85 \%$ solutions of sulfuric acid in water. Under batch conditions, water cannot be added to the acid (unless very vigorous stirring is used) due to the strong exothermicity of the reaction $(95 \mathrm{~kJ} / \mathrm{mol}) .^{24-27}$ This implies that instead of diluting oleum (fuming sulfuric acid) or concentrated sulfuric acid to $85 \%$, the production starts with

Special Issue: CAMURE11-ISMR10

Received: July 15, 2021

Revised: September 14, 2021

Accepted: September 17, 2021 


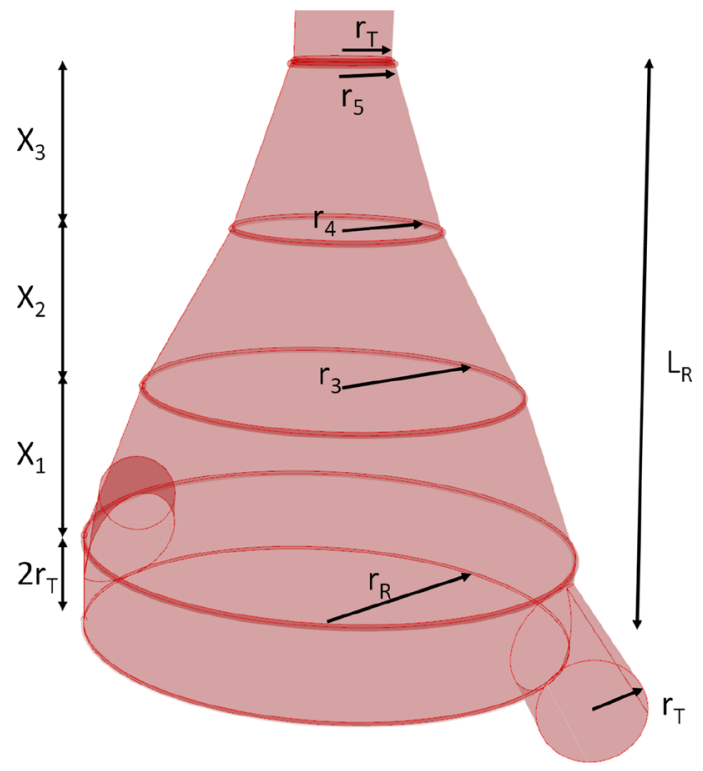

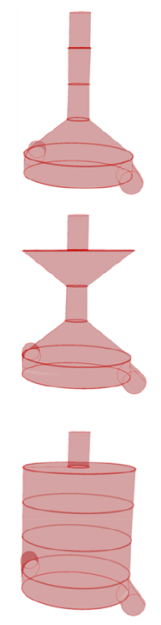

Limiting cases

of geometry

Figure 1. Scheme of the parametric Hartridge-Roughton reactor highlighting the curves used for its shape optimization and showing three possible geometries.

water. ${ }^{28}$ The sulfuric acid concentration path is then from $0 \rightarrow$ $85 \%$ instead of the shorter and more logical one: $98 \rightarrow 85 \%$ followed in large-scale continuous dilution units. The reason for taking this route is that the heat of reaction cannot be dissipated as fast as it is formed, so the water boils in the point of mixing unless a very vigorous stirring takes place. To enhance the heat transfer, industrial units for continuous sulfuric acid dilution are basically heat exchangers with annular feed and manufactured using materials with high heat conductivity, like graphite. ${ }^{29}$

This work reports the steps taken to design, manufacture, and test a reactor for dilution of sulfuric acid that can be produced in a single step by using $3 \mathrm{D}$ printing as the manufacturing technology. A Hartridge-Roughton mixer was designed and optimized for heat transfer using lattices to increase surface area. Hartridge-Roughton mixers are known to operate well in low and intermediate Reynolds numbers. ${ }^{30-35}$ A good mixer in the low Reynolds region is ideal for this application because the reaction is fast, and the rate of heat generation should be controlled by dosing the right amount of products. Otherwise, if the inlet flow of reactants is too high, it will be difficult to keep a good heat transfer.

\section{REACTOR DESIGN}

The production of reactors by $3 \mathrm{D}$ printing starts digitally. Instead of viewing the process of designing a shape in the computer as a tedious operation, it can be viewed as a fundamental step with the final aim of optimizing the topology of the reactor. In this work, topology describes the digital geometry designed in the computer and not the final surface rugosity where the resolution of the printer is involved. For a case where the type of reactor (and reaction) was already decided, the shape selection/optimization can be done by implementing a parametric design of the geometry that will be used. In this work, the Hartridge-Roughton reactor has been constructed by lofting a series of parametric curves. In its initial version, the curves were circles with varying radius and fixed at equidistant position $X_{i}$ given by

$$
X_{i}=\left(L_{R}-2 r_{T}\right) \frac{i}{3}+2 r_{T}
$$

where $L_{R}$ is the length of the reactor, and $r_{T}$ is the radius of the inlet tubes.

The target function used for shape optimization has an enormous influence on the results obtained. If the total area of the reactor $\left(S A_{R}\right)$ is the only parameter to be maximized, a cylindric design will be obtained where $r_{3}=r_{4}=r_{5}=r_{R}$, as shown in Figure 1. If the ratio of the reactor area and reactor volume $\left(V_{R}\right)$ is used, then the effect in minimizing the volume of the reactor prevails, and the optimization renders $r_{3}=r_{4}=r_{T}$ and $r_{5}=$ $r_{R}$. The option to define the volume of the reactor in the optimization function allowed a certain degree of geometry optimization. The volume used as target $\left(V_{R}^{T}\right)$ is an average of the volume obtained in the two extreme cases presented before. In this case, the optimization function was

$$
y=\frac{S A_{R}}{\left|V_{R}-V_{R}^{T}\right|}
$$

The design of the reactor was done in Grasshopper, the parametric tool of Rhino3D (McNeel \& Assoc., USA). The optimization was performed using the evolutionary solver (genetic algorithm) implemented in the Galapagos routine. The genetic algorithm in the Galapagos routine treats the individual values of each variable (termed as genes) as a genome. The genes in this work are $r_{3}, r_{4}$, and $r_{5}$, and they are defined over a range covering numerical values from $1.5-8.0 \mathrm{~mm}$ with intervals of $0.1 \mathrm{~mm}$. The genetic algorithm used is described in detail elsewhere. ${ }^{36,37}$ In this work, the algorithm has been used to maximize the reactor area using the function presented in eq 2 as a fitness function.

A video of the optimizer calculating the optimal configuration is available as Supporting Information. Using this optimization function, the values obtained are $r_{3}=0.908\left(r_{R}-r_{T}\right), r_{4}=$ $0.553\left(r_{R}-r_{T}\right)$, and $r_{5}=0.261\left(r_{R}-r_{T}\right)$. This means that a conical reactor is obtained. The design also allows the positioning of the inlet tubes so that the inlet vorticity can be tuned according to the initial feed velocity. The parametric 

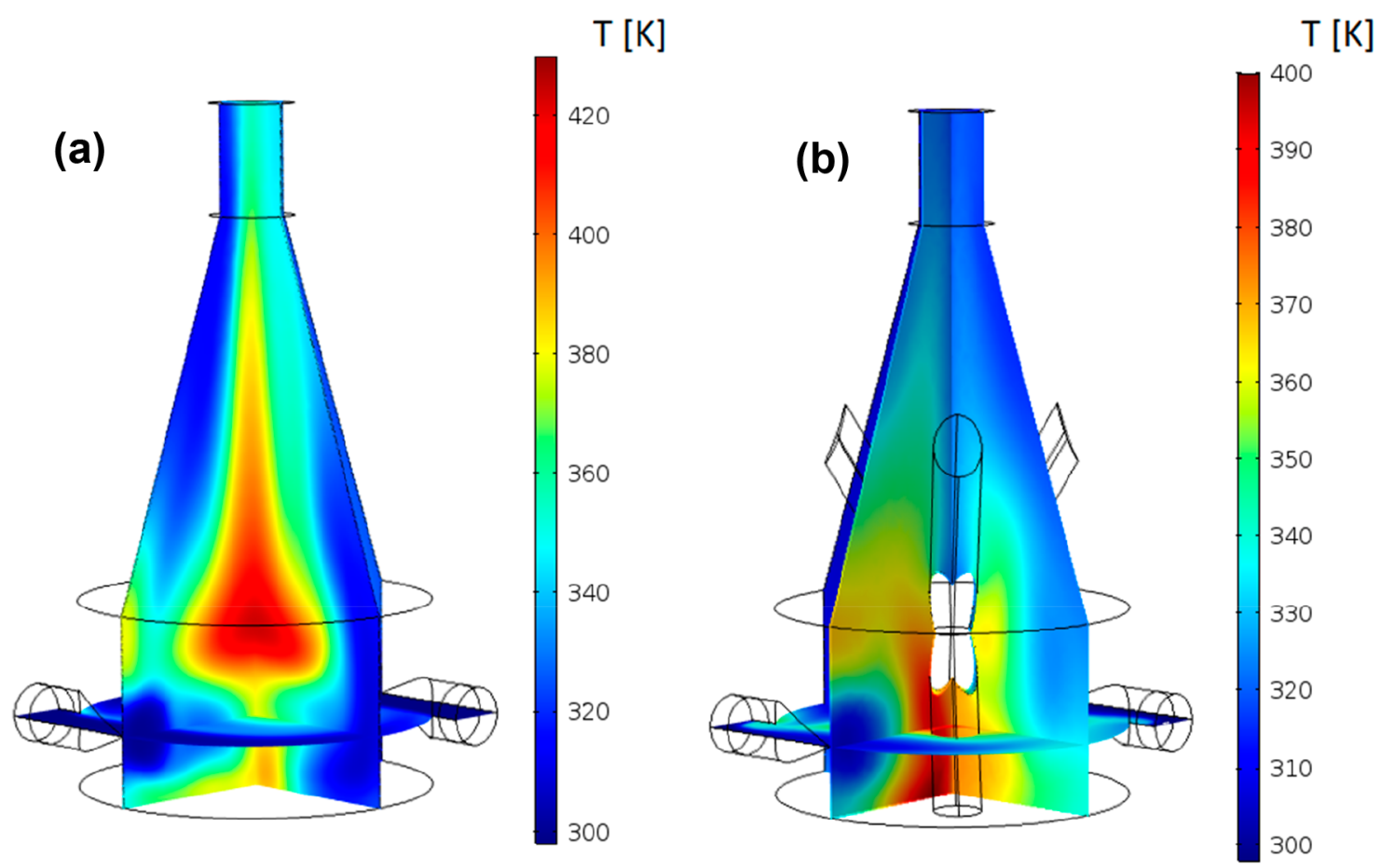

Figure 2. Temperature profiles in different places in the 3D printed reactor (a) without a lattice and (b) with an internal lattice for enhanced heat transfer.

design used is shown in Figure 1. With this design, it is possible to vary the geometry of the reactor, and some different limiting cases of the geometry are also shown in Figure 1. Setting a step size of $0.1 \mathrm{~mm}$ in a design region from the inlet radius to the maximum reactor radius $\left(r_{R}\right)$, it is easy to exceed 1000 possible reactor configurations. The curves are straight-lofted to obtain a solid with a specific volume and area. The inlet port with a tube radius $\left(r_{T}\right)$ can be moved in one axis from $\left(0, r_{R}-r_{T}\right)$ to avoid lack of consistency (nonmanifold, naked vertices, etc.) in forming the solid.

\section{INCREASE OF HEAT TRANSFER}

A major advantage of having a digital design of the reactor is that the shape can be used to perform computational fluid dynamic (CFD) simulations to understand the performance of the unit. For CFD simulations involving heat transfer, it is important to know the heat transfer coefficient inside the reactor and outside the reactor, which is, a priori, unknown. If a generic value of 100 $\mathrm{W} / \mathrm{m}^{2} / \mathrm{K}$ is used for the heat transfer to the external environment (assuming that cooling water will be used), it would be possible to take additional actions to improve the heat transfer of the reactor. The initial simulation of the HartridgeRoughton reactor is shown in Figure 2a. As can be observed, in the center of the reactor where there is less mixing taking place, the temperature of the reactants increases dramatically which is not good for the operation of the reactor and for the corrosion of the metal to be used.

A fundamental advantage of using $3 \mathrm{D}$ printing is that additional customization or introduction of distinctive features to improve the performance of the reactor does not increase dramatically the cost of production. In this work, lattices (sometimes called POCS as per periodic open cellular structures) were used to increase the available surface area for heat transfer.
Four units were designed: (a) the Hartridge-Roughton reactor as shown in Figure 1 printed over a small lattice support, (b) the reactor manufactured over a small support with a single internal octahedral cell, (c) the reactor covered with an external octahedral lattice, and (d) the reactor printed with an external and an internal lattice structure. In this work, the focus was given to the reactors with the internal lattice because the heat transfer is dominated by the heat transfer inside the reactor.

The role of the internal cell has a double function: the main role is to enhance the heat transfer of the reactor, but it also contributes to reduce the stagnant zone in the center of the reactor (the center of the octagonal cell is placed in the middle of the stagnant zone, reducing its volume). A simulation of the performance of the reactor using the same conditions as in the reference case is shown in Figure $2 \mathrm{~b}$. A significant temperature reduction is observed when introducing the internal single octagonal cell.

The sketch and the actual pictures of the reference and the reactor with internal lattice are shown in Figure 3. Pictures of all the reactors produced, including the ones with the external lattice, are shown in the Supporting Information. Grasshopper has several plug-ins to generate lattices. In this work, parts of the Intralattice plug-in were used to generate the internal and external curves constituting the lattices. The conversion of the generated lattice grid to a solid was done using in-house tools that enhance the resolution of the desired shapes.

The detailed dimensions of the reactor used are given in the Supporting Information. The final version of the code to generate the reactor is parametric and can be adapted to different sizes. The lattices (internal and external) can also be changed according to the application to tailor the surface area to volume ratio. Both lattices can be tuned to increase heat transfer in different locations of the reactor if needed. 

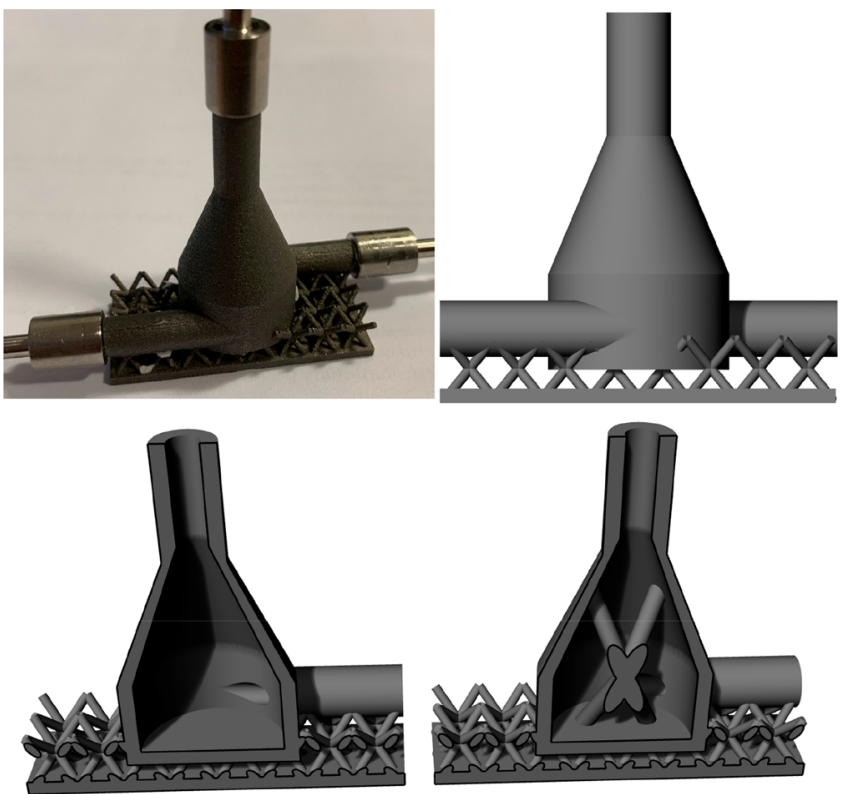

Figure 3. Picture of the 3D printed reactor in the Ti64 alloy and different views of its design: lateral view and a view of the internal geometry without (bottom left) and with internal lattice (bottom right).

\section{REACTOR MANUFACTURING AND TEST UNIT}

The reactors have to be designed to be manufactured by $3 \mathrm{D}$ printing. If a design is also not tailored to be produced by the adequate $3 \mathrm{D}$ printing technique, it will require a great amount of material for supports and much additional work of postprocessing. The reactors described in this work were manufactured using DMLS (Direct Metal Laser Sintering). The material of choice is titanium to minimize corrosion. Titanium alloy Ti64 was used as it is one standard material offered by many manufacturers.

The reactor shown in Figure 1 will need supports to be printed (or will require a redesign of the entering tubes to printable angles). Keeping in mind the possibility of scaling-up the results, a small support grid was used. If the reactor will be placed in a closed container to circulate water from its surroundings, having this small and simple support structure allows printability and can also help to mechanically adapt the reactor. The grid in the small support and the internal grid were also designed, taking into consideration angles and parameters for DMLS printers; if correctly designed, the internal and the external lattices will indeed help in the mechanical stability of the reactor.

To test the possibility of direct manufacturing by industrial partners that do not own a 3D printer of metals, the designs lay within technical specifications of external services for 3D printing (available for anyone). While the 3D printers used can tolerate smaller dimensions (width of reactors and of lattice to increase surface area), more conservative dimensions that ensure printability are customary. Three different providers were used; the machine used was in all cases an EOS machine ( 280 or 290), and their titanium alloy (Ti64) was used in all cases. Due to a confidentiality agreement signed with at least one manufacturer, we cannot disclose where the parts have been produced.

A simple layout of the experimental system used for the continuous reaction is shown in the Supporting Information. The equipment consists of two HPLC pumps, one for water and the other for sulfuric acid, connected to the two inlets of the reactor. The inlet tubes of the reactors were positioned in the bottom to avoid changes in the flow pattern due to differences in the density of the reactants. The outlet of the reactor is connected to a container where the product is collected and with enough volume to neutralize it before it is safely discarded. Temperature was measured at four points: at the two inlet streams, at the outlet stream, and in the water bath where the reactor was placed. To be able to increase the safety of the experiments, the water in the bath where the reactor was immersed has a $\mathrm{pH}$ indicator to indicate any fast reactor or system leakages. Temperature was measured with $1 \mathrm{~s}$ intervals using $\mathrm{K}$ thermocouples. Experiments were made using inlet flow rates of $3 \mathrm{~mL} / \mathrm{min}$ of each reactant (symmetric mixture) and

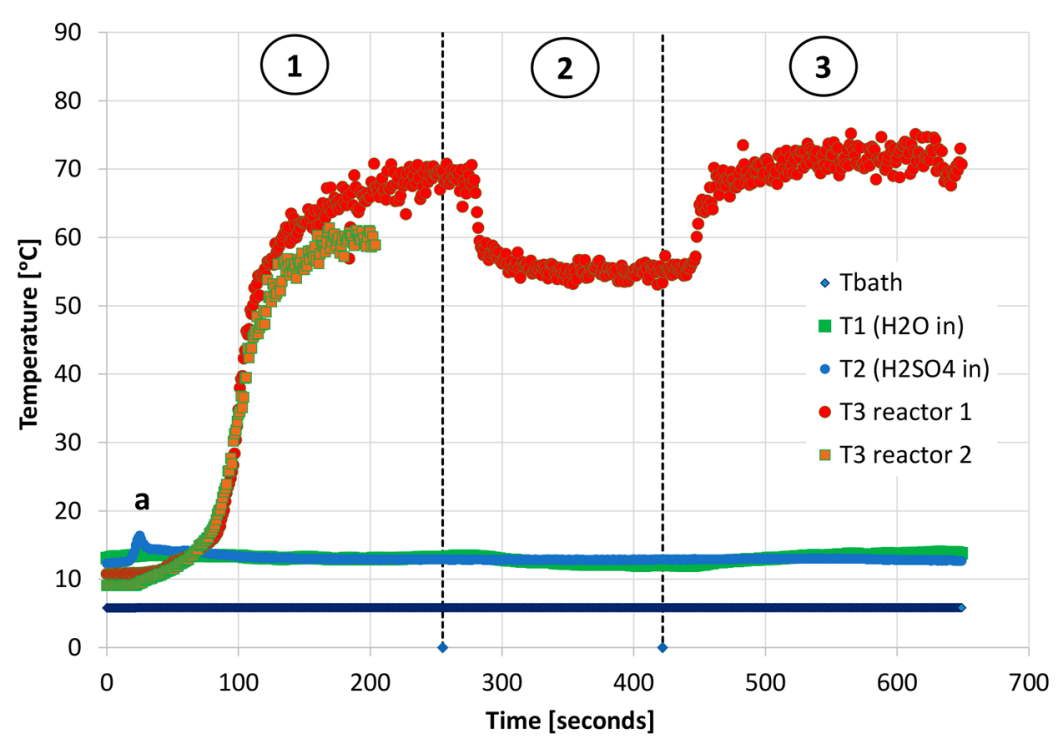

Figure 4. Operation of the Hartridge-Roughton reactor 1 for dilution of sulfuric acid. Initially (1) the feed is $3.0 \mathrm{~mL} / \mathrm{min}$ of $\mathrm{H}_{2} \mathrm{O}$ and $\mathrm{H}_{2} \mathrm{SO}_{4}$. In $(2)$, it is $1.5 \mathrm{~mL} / \mathrm{min}_{2} \mathrm{O}$ and $3.0 \mathrm{~mL} / \mathrm{min}_{2} \mathrm{SO}_{4}$, and in (3), it is $3.0 \mathrm{~mL} / \mathrm{min}_{2} \mathrm{O}$ and $1.5 \mathrm{~mL} / \mathrm{min}_{2} \mathrm{SO}_{4}$. The exit temperature of reactor 2 for case 3 (3.0 $\mathrm{mL} / \mathrm{min} \mathrm{H}_{2} \mathrm{O}$ and $1.5 \mathrm{~mL} / \mathrm{min}_{2} \mathrm{SO}_{4}$ ) is also plotted for comparison. 

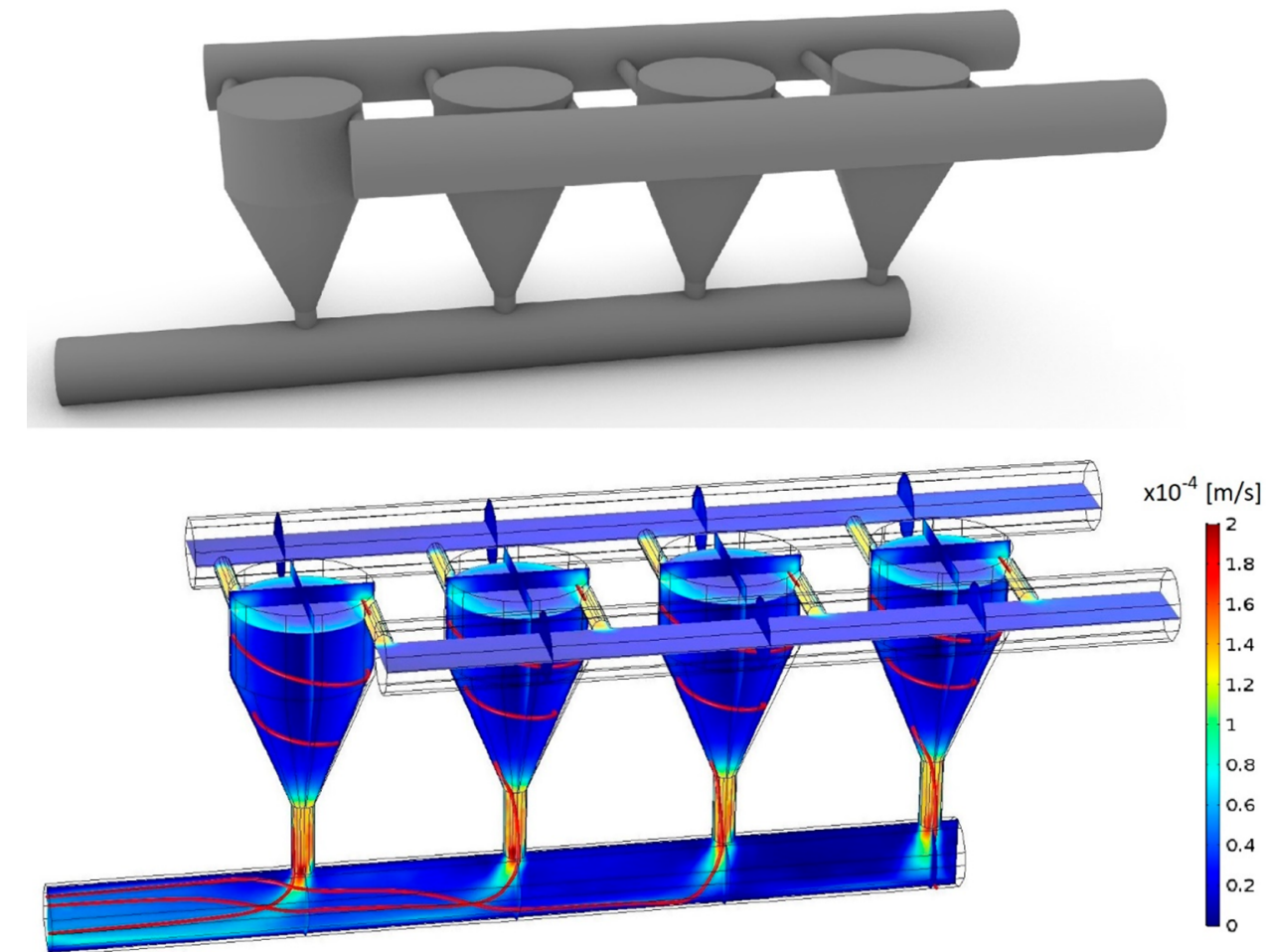

Figure 5. Possible design of a scaled-up version of the reactor (top) and the simulation of liquid velocity exiting the reactor to denote that there are no preferential paths in this reactor design.

asymmetric mixtures: $3.0 \mathrm{~mL} / \mathrm{min} \mathrm{H}_{2} \mathrm{O}$ and $1.5 \mathrm{~mL} / \mathrm{min}_{2} \mathrm{SO}_{4}$ and $1.5 \mathrm{~mL} / \mathrm{min} \mathrm{H}_{2} \mathrm{O}$ and $3.0 \mathrm{~mL} / \mathrm{min}_{2} \mathrm{SO}_{4}$. Experiments were made with the two reactors shown in Figure 3. The sulfuric acid used is Merck 258105, ACS reagent 95.0-98.0\%. Deionized water with a conductivity of $20.9 \mathrm{M} \Omega \cdot \mathrm{cm}$ was used.

\section{RESULTS AND DISCUSSION}

Dilution of Sulfuric Acid. The computational fluid dynamic (CFD) simulations of the reactor shown in Figure 2 were performed to understand the operation of the unit. To avoid the possible high temperatures observed in the simulations, the reactors were placed in a water bath with ice that allows the inlet temperature of the inlet fluids to be close to $10^{\circ} \mathrm{C}$. A pH indicator was used in the water to check whether there were leaks.

The temperature at the exit of reactor 1 reaches $70{ }^{\circ} \mathrm{C}$. The temperature increase is very sharp because the reaction is very fast and very exothermic. No additional temperature increase has been observed in the collector of the exiting mixture indicating that the reactants were well mixed in the reactor. This was expected because the hydration reaction is quite fast, and the residence time with $6 \mathrm{~mL} / \mathrm{min}$ of inlet flow rate $(3 \mathrm{~mL} / \mathrm{min}$ of each reactant) is approximately $20 \mathrm{~s}$. The exiting diameter of the exit tube of the reactor has the same diameter as each of the inlets, so the exiting fluid is accelerated at the exit of the reactor. The approach to the steady state in the reactor 1 for the case of the symmetric mixture is shown in Figure 4. The exit temperature obtained with the second reactor is also shown in that figure. Note that the comparison was made using different conditions; the first experiment in the second reactor is the asymmetric one $\left(3.0 \mathrm{~mL} / \mathrm{min} \mathrm{H}_{2} \mathrm{O}\right.$ and $\left.1.5 \mathrm{~mL} / \mathrm{min}_{2} \mathrm{SO}_{4}\right)$ that releases the largest amount of heat. These experiments show the importance of the topology of the reactor. Indeed, with a very small modification of the reactor, a significant reduction of temperature is achieved. Moreover, the lattice introduced inside the reactor helped the structure to be easier to be built by DMLS. For comparison, an experiment with the reactor that has an external lattice was made. In principle, if the heat transfer is controlled in the inner part of the reactor, the experimental results with the reactor having a larger surface area on the external surface should render the same results. Experimentally, a temperature of $74{ }^{\circ} \mathrm{C}$ was achieved with the symmetric run, and the highest temperature of $84{ }^{\circ} \mathrm{C}$ was achieved with the largest amount of water $\left(3.0 \mathrm{~mL} / \mathrm{min} \mathrm{H}_{2} \mathrm{O}\right.$ and $1.5 \mathrm{~mL} / \mathrm{min}$ $\left.\mathrm{H}_{2} \mathrm{SO}_{4}\right)$. Indeed, if the reactor is immersed in a bath with static water, the external lattice will make the convective movement of water with different temperatures more difficult resulting in a net poorer heat transfer.

Interaction between Design and Performance: Scaleup and Corrosion. As it has been shown by the previous examples, the tailoring of reactors can be done in different phases to obtain a design that performs a desired operation. In this initial work, the topology optimization rendered different limiting cases that were further evaluated by CFD simulations. A more advanced optimization would link directly the shape optimization with tools that allow a simultaneous prediction of the heat exchange and the hydrodynamics of the system. Only then, the full topology optimization will be implemented. ${ }^{38}$ With existing tools, such an approach is computationally expensive and is so far limited to small reactors.

The optimization can be related to the scale-up of these reactors, but using advanced manufacturing, this issue can be partially decoupled. There are several possible methods to scaleup the reactor used in this work, and at least two will be mentioned:

1 The volume of the reactor is increased, and the ratio between the volume of the reactor and the metal lattice is 
maintained. In this case, the size of the lattice cell should be studied to understand if the reactor will behave identically. Alternatively, more than one cell is used while keeping the reactor volume to metal ratio.

2 If the heat transfer is limited in the internal volume of the reactor, a multireactor system can be constructed. In this configuration, the feed of an exhaust system is used to distribute the feed and collect the product to different reactors operating in parallel. A picture of this reactor is depicted in Figure 5 together with a CFD simulation indicating that there is no preferential path in one of the reactors. Using traditional manufacturing, this process will increase the cost linearly. With $3 \mathrm{D}$ printing, the cost is a function not only of reactor weight and volume but also of $3 \mathrm{D}$ printing time, so an efficient design can contribute in cost reduction.

A major advantage of the $3 \mathrm{D}$ printing technology is that the manufacturing starts digitally, so many advanced modeling options can be used to optimize the reactor even before manufacturing. A good parametric design also helps with the understanding of the system. This is particularly important for a fully optimized design, where all reactor parts are interlinked and safely connected. In this work, the reactor design was made sequentially; a view of the different components is given in Figure S5 in the Supporting Information. The sequential design performed here allows the generation of individual shapes both at the reactor level and at the internal-external lattices as well as the external layout. Such independent design can allow a faster change of dimensions, a tailored scale-up, and also the generation of individual stls or cad images that can be used for optimization of each of the parts if desired. An important lesson from this work is that good attention should be paid to the inletoutlet port connectors. The ports in this reactor were not fully customized, and it was difficult to find solutions to avoid leakages. Our learning is that the ports should be adapted to adapt standard solutions already available for current systems.

Another important aspect to produce these reactors is that all measures to reduce the cost of production should be taken at the design phase. The cost is strongly driven by costs of material used, printing time, and printer depreciation, and it can also be influenced by necessary postprocessing. The reactors shown in this work were used without any postprocessing techniques to reduce the surface rugosity (internal or external). Postprocessing techniques to reduce the rugosity in intricated geometries with lattices can be very expensive. The use of supports should also be done with caution to reduce costs; they require additional material that will not be further used and postprocessing. In this work, the supports used were providing structural support to the final wall, so they were not removed. Lack of normative for production of $3 \mathrm{D}$ printed reactors makes it difficult to estimate final costs of larger units.

Perhaps one of the most interesting parts to be fully understood before expecting commercialization of these reactors is related to the building material. As mentioned before, the reactors were built in different places but using the same titanium alloy (Ti64) and similar machines. The parameters of each of these machines are established (and eventually tailored) by each of the manufacturers, and we do not have access to them. The first observation is that in the reactors with the external lattice, the topology of one of the reactors was slightly more rugous than the rest. The rugosity on the external parts does not need to be the same as in the internal parts. The topology of one of the reactors determined by light interferometry is shown in the Supporting Information. This rugosity is comparable to other reactors that our group has printed before and is according to expectations.

What needs to be better understood, particularly for internal lattices, is whether the extra rugosity of the $3 \mathrm{D}$ printing process by DMLS is going to create local corrosion points in different locations of the reactor. This is particularly crucial for regions with higher velocity and/or where higher temperatures are achieved. For titanium, sulfuric acid can be corrosive, particularly at higher temperatures. ${ }^{39}$ Indeed, when cleaning one of the reactors, a slight smell of $\mathrm{SO}_{2}$ was detected. This denotes the possibility of some possible reduction of diluted sulfuric acid by oxidation of the titanium surface although no detectable changes in reactor surface rugosity were observed after the experimental campaign. Long-term studies on this issue are necessary to establish an operative time limit and eventual preferred concentration range of operability.

Another very interesting feature of the reactors manufactured in different places is that the color and brightness of the reactors is not the same. Such a small color change is very difficult to be caught on camera, and therefore a picture is not reported. DMLS printers are rather expensive pieces of equipment, and in some places, the machines are used for printing batches with different materials. In such cases, it may happen that there is crosscontamination of different powders used or that some powder from the previous batch remained in the unit. This crosscontamination can be very problematic when working in extremely corrosive environments, and a large degree of attention should be paid to this for those applications. Indeed, one of the reactors could not handle the operation and started leaking after the first set of experiments in contact with the sulfuric acid solution; for confidentiality issues, we cannot disclose the type or the degree of contamination in each of the reactors. For this reason, specific procedures should be still developed to create normative standards for such reactors before their commercialization.

\section{CONCLUSIONS}

In this work, we designed, modeled, manufactured, and tested a tailored reactor for performing a corrosive and exothermic reaction. The reaction used in this work is the dilution of sulfuric acid with water. A parametric design of a Hartridge-Roughton reactor was done and used to optimize its shape for creating a larger surface area per reactor volume with a good mixing inside the reactor. Inserting an internal lattice increased enormously the heat transfer properties of the reactor and allowed the performance of the reaction in a controlled manner. Inserting such a lattice using a standard manufacturing technology would be complicated, but with using $3 \mathrm{D}$ printing, the lattice indeed helps in the construction of the unit. Different designs of the reactor are also proposed to scale-up the unit to industrially relevant levels. All these designs can be manufactured with existing 3D metal printers. An issue that must be solved before commercialization of reactors for difficult environments (corrosive and exothermic reactions) is the evaluation of the material upon manufacturing. In our study, different providers were used, and the different colors in the final product may indicate cross-contamination of the Ti64 alloy with other powders. This indicates that specific procedures should be still developed to create normative standards for such reactors before their commercialization. 


\section{ASSOCIATED CONTENT}

\section{(s) Supporting Information}

The Supporting Information is available free of charge at https://pubs.acs.org/doi/10.1021/acs.iecr.1c02791.

Figures S1-S6: images of 3D printed reactors produced, pictures of reactors with and without external lattices, dimensions of reactors without external lattice, layout of experimental setup, Grasshopper code section for parametric design, and rugosity of reactors determined by light interferometry (PDF)

Video of genetic algorithm for optimization of surface area (MP4)

\section{AUTHOR INFORMATION}

\section{Corresponding Author}

Carlos A. Grande - SINTEF Industry, 0373 Oslo, Norway; Advanced Membranes and Porous Materials (AMPM) Center \& Kaust Catalysis Center (KCC), King Abdullah University of Science and Technology (KAUST), Thuwal 23955-6900, Saudi Arabia; 이이이.org/0000-0002-9558-5413;

Email: carlos.grande@kaust.edu.sa

\section{Author}

Terje Didriksen - SINTEF Industry, 0373 Oslo, Norway

Complete contact information is available at:

https://pubs.acs.org/10.1021/acs.iecr.1c02791

\section{Notes}

The authors declare no competing financial interest.

\section{REFERENCES}

(1) Mitic, A.; Gernaey, K. V. Process Intensification Tools in the Small-Scale Pharmaceutical Manufacturing of Small Molecules. Chem. Eng. Technol. 2015, 38 (10), 1699-1712.

(2) Commenge, J.-M.; Falk, L.; Matlosz, C. M. Analysis of Microstructured Reactor Characteristics for Process Miniaturization and Intensification. Chem. Eng. Technol. 2005, 28 (4), 446-458.

(3) Voros, V.; Drioli, E.; Fonte, C.; Szekely, G. Process Intensification via Continuous and Simultaneous Isolation of Antioxidants: An Upcycling Approach for Olive Leaf Waste. ACS Sustainable Chem. Eng. 2019, 7 (22), 18444-18452.

(4) Martin, B.; Lehmann, H.; Yang, H.; Chen, L.; Tian, X.; Polenk, J.; Schenkel, B. Continuous manufacturing as an enabling tool with green credentials in early-phase pharmaceutical chemistry. Curr. Op. Green. Sust. Chem. 2018, 11, 27-33.

(5) Jensen, K. F. Flow chemistry - Microreaction technology comes of age. AIChE J. 2017, 63, 858-869.

(6) Chen, C.; Wong, H. E.; Goudar, C. T. Upstream process intensification and continuous manufacturing. Curr. Opin. Chem. Eng. 2018, 22, 191-198.

(7) Khinast, J.; Rantanen, J. Continuouus manufacturing of pharmaceuticals; John Wiley \& Sons Ltd.: 2017; DOI: 10.1002/ 9781119001348.

(8) Rogers, K.; Jensen, K. F. Continuous manufacturing - the green chemistry promise? Green Chem. 2019, 21, 3481-3498.

(9) Buchholz, S. Future manufacturing approaches in the chemical and pharmaceutical industry. Chem. Eng. Process. 2010, 49, 993-995.

(10) Costandy, J. G.; Edgar, T. F.; Baldea, M. Switching from Batch to Continuous Reactors Is a Trajectory Optimization Problem. Ind. Eng. Chem. Res. 2019, 58 (30), 13718-13736.

(11) Pfizer Showcase Industrial-scale Continuous Manufacturing! 2021. Available at https://chemtrix.com/news/pfizer-showcaseindustrial-scale-continuous-manufacturing (accessed 2021-09-14).

(12) Dunn, A. L.; Payne, A.; Clark, P. R.; McKay, C.; Williams, G. D.; Wheelhouse, K.; Arendt, K.; Dixon, F.; Shilcrat, S. Process Safety in the
Pharmaceutical Industry: A Selection of Illustrative Case Studies. J. Chem. Educ. 2021, 98 (1), 175-182.

(13) Tian, Y.; Zhang, X.; Yu, B.; Bai, Y.; Guan, L.; Teng, S.; Li, J.; Huang, C.; Lanz, M.; Hoehn, P. Case-Based Thermal Safety Evaluation on a Pharmaceutical Process Using Dimethyl Sulfoxide as a Solvent. Org. Process Res. Dev. 2020, 24 (12), 2927-2934.

(14) Von Keutz, T.; Williams, J. D.; Kappe, C. O. Continuous Flow CGlycosylation via Metal-Halogen Exchange: Process Understanding and Improvements toward Efficient Manufacturing of Remdesivir. Org. Process Res. Dev. 2020, 24 (10), 2362-2368.

(15) Sun, X.; Wang, Z.; Li, C.; Zhang, L.; Yang, W.; Tao, S. Threedimensional-printed holistic reactors with fractal structure for heterogeneous reaction. AIChE J. 2021, 67, No. e17298.

(16) Sans, V. Emerging trends in flow chemistry enabled by $3 \mathrm{D}$ printing: Robust reactors, biocatalysis and electrochemistry. Curr. Op. Green Sust. Chem. 2020, 25, 100367.

(17) Parra-Cabrera, C.; Achille, C.; Kuhn, S.; Ameloot, R. 3D printing in chemical engineering and catalytic technology: structured catalysts, mixers and reactors. Chem. Soc. Rev. 2018, 47, 209-230.

(18) Sagandira, C. R.; Siyawamwaya, M.; Watts, P. 3D printing and continuous flow chemistry technology to advance pharmaceutical manufacturing in developing countries. Arabian J. Chem. 2020, 13, 7886-7908

(19) Kitson, P. J.; Rosnes, M. H.; Sans, V.; Dragone, V.; Cronin, L. Configurable 3D-Printed millifluidic and microfluidic 'lab on a chip' reactionware devices. Lab Chip 2012, 12, 3267-3271.

(20) Vogel, A. P.; Nel, H. G.; Stadler, J. A.; Jordi, R. G.; Breman, B. B. Intensification of the Sasol SPD Reactor - Realizing Potential. Ind. Eng. Chem. Res. 2014, 53 (5), 1768-1774.

(21) Gutmann, B.; Köckinger, M.; Glotz, G.; Ciaglia, T.; Slama, E.; Zadravec, M.; Pfanner, S.; Maier, M. C.; Gruber-Wöfler, H.; Oliver Kappe, C. Design and 3D printing of a stainless steel reactor for continuous difluoromethylations using fluoroform. React. Chem. Eng. 2017, 2, 919-927.

(22) Mohammad, N.; Abrokwah, R. Y.; Stevens-Boyd, R. G.; Aravamudhan, S.; Kuila, D. Fischer-Tropsch studies in a 3D-printed stainless steel microchannel microreactor coated with cobalt-based bimetallic-MCM-41 catalysts. Catal. Today 2020, 358, 303-315.

(23) Fratalocchi, L.; Groppi, G.; Visconti, C. G.; Lietti, L.; Tronconi, E. Packed-POCS with skin: A novel concept for the intensification of non-adiabatic catalytic processes demonstrated in the case of the Fischer-Tropsch synthesis. Catal. Today 2021, DOI: 10.1016/ j.cattod.2020.12.031.

(24) Giauque, W. F.; Hornung, E. W.; Kunzler, J. E.; Rubin, T. R. The thermodynamic properties of aqueous sulfuric acid solutions and hydrates from 15 to 300 K. J. Am. Chem. Soc. 1960, 82, 62-70.

(25) Kim, S. H.; Roth, M. Enthalpies of dilution and excess molar enthalpies of an aqueous solution of sulfuric acid. J. Chem. Eng. Data 2001, 46, 138-143.

(26) Wu, Y. C.; Young, T. F. Enthalpies of Dilution of Aqueous Electrolytes: Sulfuric Acid, Hydrochloric Acid, and Lithium Chloride. J. Res. Natl. Bur. Stand. 1980, 85, 11-17.

(27) Teja, A. S. Simple method for the calculation of heat capacities of liquid mixtures. J. Chem. Eng. Data 1983, 28, 83-85.

(28) Ablaze Export PVT, LTD. Sulfuric acid dilution plant. Available at https://www.ablazeexport.com/sulfuric-acid-dilution-plant/ (accessed 2021-09-12).

(29) https://www.gab-neumann.com/sulfuric-acid-dilution (accessed 2021-09-14).

(30) Hartridge, H.; Roughton, F. J. W. A method of measuring the velocity of very rapid chemical reactions. Proc. R. Soc. London 1923, A104, 376-394.

(31) Koiranen, T.; Woldemariam, M.; Salminen, A. Reactor Performance and Design Concept in Additively Manufactured MilliScale Reactors. J. Chem. Eng. Process Technol. 2017, 8, 1000363.

(32) Ottino, J. M. Mixing and chemical reactions: a tutorial. Chem. Eng. Sci. 1994, 49, 4005-4027. 
(33) Lindenberg, C.; Schöll, J.; Vicum, L.; Mazzotti, M.; Brozio, J. Experimental characterization and multi-scale modeling of mixing in static mixers. Chem. Eng. Sci. 2008, 63, 4135-4149.

(34) Lindenberg, C.; Mazzotti, M. Experimental characterization and multi-scale modeling of mixing in static mixers. Part 2. Effect of viscosity and scale-up. Chem. Eng. Sci. 2009, 64, 4286-4294.

(35) Di Patrizio, N.; Bagnaro, M.; Gaunand, A.; Hochepied, J.-F.; Horbez, D.; Pitiot, P. Hydrodynamics and mixing performance of Hartridge Roughton mixers: Influence of the mixing chamber design. Chem. Eng. J. 2016, 283, 375-387.

(36) Rutten, D. Evolutionary Principles applied to Problem Solving. September 2010. Available at https://www.grasshopper3d.com/ profiles/blogs/evolutionary-principles (accessed 2021-09-13).

(37) Wortmann, T. Model-based Optimization for Architectural Design: Optimizing Daylight and Glare in Grasshopper. Technology I Architecture + Design 2017, 1, 176-185.

(38) Courtais, A.; Lesage, F.; Privat, Y.; Pelaingre, C.; Latifi, A. M. Optimal design of a structured fixed-bed reactor using geometry optimization and Stratoconception printing process. Comput. Chem. Eng. 2021, 153, 107405.

(39) Ban, S.; Iwaya, Y.; Kono, H.; Sato, H. Surface modification of titanium by etching in concentrated sulfuric acid. Dent. Mater. 2006, 22, $1115-1120$. 